\title{
REVIEW
}

\section{NF-kB-regulated, proinflammatory miRNAs in Alzheimer's disease}

\author{
Walter J Lukiw*
}

\begin{abstract}
Abundant neurochemical, neuropathological, and genetic evidence suggests that a critical number of proinflammatory and innate immune system-associated factors are involved in the underlying pathological pathways that drive the sporadic Alzheimer's disease (AD) process. Most recently, a series of epigenetic factors - including a select family of inducible, proinflammatory, NF-kB-regulated small noncoding RNAs called miRNAs - have been shown to be significantly elevated in abundance in AD brain. These upregulated miRNAs appear to be instrumental in reshaping the human brain transcriptome. This reorganization of mRNA speciation and complexity in turn drives proinflammatory and pathogenic gene expression programs. The ensuing, progressively altered immune and inflammatory signaling patterns in AD brain support immunopathogenetic events and proinflammatory features of the AD phenotype. This report will briefly review what is known concerning NF-KB-inducible miRNAs that are significantly upregulated in AD-targeted anatomical regions of degenerating human brain cells and tissues. Quenching of NF-KB-sensitive inflammatory miRNA signaling using NF-KB-inhibitors such as the polyphenolic resveratrol analog trans-3,5,4'-trihydroxystilbene (CAY10512) may have some therapeutic value in reducing inflammatory neurodegeneration. Antagonism of NF-KB-inducing, and hence proinflammatory, epigenetic and environmental factors, such as the neurotrophic herpes simplex virus-1 and exposure to the potent neurotoxin aluminum, are briefly discussed. Early reports further indicate that miRNA neutralization employing anti-miRNA (antagomir) strategies may hold future promise in the clinical management of this insidious neurological disorder and expanding healthcare concern.
\end{abstract}

\section{Introduction}

Although intensively studied for well over 100 years, the biological factors that initiate and drive the Alzheimer's disease $(\mathrm{AD})$ process remain incompletely understood [1-3]. Anti-AD therapies directed solely against amyloid beta $(A \beta)$ peptides have generally proved extremely disappointing, although therapeutic strategies targeted against multiple AD biomarkers - such as amyloid and tau abundance and processing dysfunction and neuroinflammation - have more recently shown greater promise [1-4].

As one recent example, the experimental drug posiphen, a chirally pure positive enantiomer of phenserine and $\beta$ amyloid precursor protein ( $\beta \mathrm{APP}$ ) synthesis inhibitor, has shown a significantly improved efficacy against multiple AD-relevant targets, at least in proof-of-principal phase I

*Correspondence: wlukiw@lsuhsc.edu

Professor of Neurology, Neuroscience and Ophthalmology, LSU Neuroscience Center, 2020 Gravier Street, Suite 904, New Orleans, LA 70112, USA testing [4]. Interestingly, this drug has been shown not only to attenuate $A \beta 42$ peptide levels but also to lower the inflammatory biomarkers complement factor C3 and monocyte chemotactic protein in the cerebrospinal fluid of patients suffering from mild cognitive impairment [4]. Indeed, significant increases in inflammatory biomarkers such as cytokines, chemokines, complement factors, chemotactic proteins and C-reactive protein, mitochondrial-mediated upregulation of reactive oxygen species (ROS), and the proinflammatory actions of $A \beta$ peptides have long been thought to be involved in a brain-specific inflammatory process as $\mathrm{AD}$ initiates and progresses throughout the limbic system of the brain [4-13].

One neurogenetic consequence of increased inflammatory signaling in $\mathrm{AD}$ brain is the upregulation of the inducible, proinflammatory transcription factor NF- $\mathrm{KB}$, and NF-KB-driven miRNA expression; hence a self-sustaining, self-reinforcing proinflammatory signaling loop is generated [2,3,7-18]. Whether some of these proinflammatory signaling systems are neuroprotective or beneficial to homeostatic brain cell structure and 
function remains to be clarified [5-9]. Extrinsic and environmental factors such as herpes simplex virus-1 (HSV-1) infection and aluminum exposure from the environment, as two exceptionally strong inducers of $\mathrm{NF}-\mathrm{\kappa B}$ and proinflammatory miRNA upregulation, are considered potential contributors to the development of $\mathrm{AD}$ pathology. Major points regarding the potential pathogenic role for each of these factors and processes are further discussed in the following sections.

\section{Inflammation and Alzheimer's disease}

Inflammation constitutes an intrinsic, physiological defense mechanism aimed at protecting healthy tissues from infection, injury and trauma. As such, inflammation represents an essential, evolutionarily ancient process that normally ceases to function once the physiological insult has been eliminated, and cellular homeostasis has been restored [1-12]. On the contrary, chronic or sustained inflammatory signaling contributes to dyshomeostasis, culminating in progressive cellular damage as is observed in many pathological and progressive degenerative conditions ranging from cancer to $\mathrm{AD}$ [4,11-18].

In the central nervous system (CNS), macrophages and glial cells - as the primary immune cells in the brain's privileged immune compartment - function primarily, by a variety of phagocytic and digestive mechanisms, to promote host defense by maintaining tissue homeostasis through the destruction of invading pathogens, through sequestering and eliminating deleterious debris via the cytoplasmic multi-protein inflammasome complex, and by promoting tissue repair [12-39]. On the contrary, sustained, uncontrolled activation of brain macrophages and glial cells can lead to excess production of various pathogenic factors that contribute to neuronal injury, including the significant and dramatic upregulation of proinflammatory chemokines, cytokines and ROS. These in turn are capable of activating inflammatory transcription factors such as NF- $\mathrm{KB}$ and proinflammatory gene expression programs that drive cellular fate towards CNS dys-homeostasis, compromised neuronal function and, ultimately, apoptosis and brain cell death [2,3,38-48].

A strong association between inflammation and $\mathrm{AD}$ has been suggested for almost 50 years, and to date at least 2,750 peer-reviewed papers have appeared on the contribution of inflammation to the AD process [11-14]. Some of these inflammatory processes may be necessary in an attempt to regain brain cell homeostasis in early $\mathrm{AD}$, but the integration of these processes into $\mathrm{AD}$ proliferation and the progression to late-stage $\mathrm{AD}$ is not well understood [15-18]. Over the last year there have been at least half-a-dozen excellent reviews on this area of research on the $\mathrm{AD}$-inflammation connection so this topic will not be covered in depth here [5,15-20].
Briefly, AD is characterized neuropathologically by at least five heterogeneous features, all of which support the progressive generation of abnormal tau and amyloid, neural and synaptic deficits and proinflammatory signaling to various degrees. These features include: the appearance of hyperphosphorylated tau-protein containing intracellular neurofibrillary tangles; amyloidogenesis - the progressive, age-related generation, aggregation and accumulation of $\mathrm{A} \beta$ peptides into dense, insoluble, proinflammatory and pathogenic deposits of senile plaque; reduced synaptic densities and synaptic protein assemblies; significant neuronal loss in the temporal lobe and hippocampal regions that, as $\mathrm{AD}$ progresses, radiates into the more distal parietal, frontal and occipital poles of the brain; and a unique, chronic and progressive smoldering inflammation of the neocortex and limbic system of the brain, especially in the middle to late stages of $\mathrm{AD}$ [11-18,20-25].

Until recently, the density of neurofibrillary tangle and senile plaque lesions required extensive postmortem histopathological confirmation for an accurate diagnosis of AD; however, current autoradiographic, nuclear magnetic resonance, tomographic and related electronic digitization and quantification technologies are capable of non-invasively and effectively resolving these insoluble lesions in the aging brains of patients with $\mathrm{AD}$, and in transgenic animal models of AD (Tg-AD) [24-31]. Indeed, the initial aberrant phosphorylation of tau, the generation of $A \beta$ peptides, the progressive aggregation from soluble $\mathrm{A} \beta$ peptide monomers into higher-order structures, and ultimately into insoluble deposits, and their unusual protease-resistant biophysical properties have been widely suggested to be the most significant markers for early cognitive disturbances, mild cognitive impairment and early AD onset [12-18,24-32]. These markers may typically precede, by decades, the appearance of fully mature senile plaque and tangle lesions in the $\mathrm{AD}$ brain [28-32]. $A \beta 40$ and $A \beta 42$ peptides themselves, and innate immune system interaction and attack of the mature senile plaque and tangle lesions mediated by CNS macrophages and microglia, may represent one of the earliest manifestations of increased immune system activation and inflammatory signaling in $\mathrm{AD}$, and of the ensuing upregulation of chemokines, cytokines IL-1 $\beta$ and TNF $\alpha$ and others, chemotactic proteins and complement factor proteins such as complement factor $\mathrm{H}(\mathrm{CFH})$ [7-10,32-38]. That $A \beta 40$ and $A \beta 42$ peptides directly activate microglia and monocytes to progressively generate these endogenous neurotoxins may signify that $A \beta$ peptides or $A \beta$ peptide-containing lesions may be critical for the initial seeding of inflammatory neurodegeneration, as is observed in the $\mathrm{AD}$-affected brain and in amyloid-overexpressing Tg-AD models [33-39]. 


\section{Proinflammatory transcription factor NF-KB}

As previously indicated, neuroinflammatory processes appear, against a background of brain aging, to significantly contribute to a cascade of deleterious events that culminates in progressive synaptic loss and neuronal signaling dysfunction - pathogenic events that critically underlie a number of inflammatory neurodegenerative disorders including $\mathrm{AD}$, age-related macular degeneration (a common AD-like inflammatory degeneration of the human retina) and also human prion disease [16,38-48].

During upregulation of inflammatory processes in the CNS and retina there appears to be a significant parallel upregulation of the dimeric DNA-binding protein NF-кB (as the p50/p65 complex) [40-48]. Indeed, originally described in 1986, NF-кB has emerged as a ubiquitous transcription factor that controls diverse biological functions including inflammatory and immune functions in both the central and peripheral nervous systems [4045]. NF-кB may be singularly important in regulating genetic responses to nervous system stress through the innate immune response because it belongs to the category of pre-existing primary transcription factors that are already present in cells in an inactive-sensory state and do not require new protein synthesis to be activated [40-45]. That the NF-кB p50 and p65 subunits belong to an expanding family of more than 25 NF- $\mathrm{kB}$ subunits indicates that the subunit composition of NF-кB is variable and may be tailored by the cell to accommodate various inflammatory signaling needs [40,41,44-49]. Interestingly, compared with interleukin-1 receptor-associated kinase (IRAK)-1, the more chronic and persistent activation of the NF-кB p50/p65 complex via the IRAK-2 signaling pathway in $A D$ has recently been described [49]. Importantly, NF- $\mathrm{KB}$ activation and binding in the promoters of NF- $\mathrm{KB}$-sensitive genes, including miRNA precursors (see below), leads to the facilitated transcription of many hundreds of potentially pathogenic genes, and therefore has the capacity to completely overwhelm the cell's anti-oxidant and antiinflammatory defenses while at the same time altering the functional properties of nervous system cells [40-49].

\section{Speciation, bioactivity and complexity of miRNA in the human brain}

The potential contribution of small, noncoding RNA to human brain genetic function has been known for at least 20 years [50], but more recently there has been a virtual explosion into molecular-genetic research involving the neurobiological function of small, noncoding RNA and miRNA in brain development, injury, aging, health and disease [38,49,51-59]. Indeed, both small, noncoding RNAs and miRNAs are acquiring increasingly important roles in modulating the pathogenesis of progressive human neurologic disorders including inflammatory neurodegeneration, AD, Down's syndrome, epileptogenesis, glioma and glioblastoma, human prion diseases such as Creutzfeldt-Jakob disease and Gerstmann-StrausslerScheinker syndrome, viral infection and aluminum intoxication of the brain, as well in murine $\mathrm{Tg}-\mathrm{AD}$ and other transgenic models for progressive human neurodegenerative disorders [52-60].

The miRNAs represent an evolutionarily conserved class of single-stranded small, noncoding RNAs averaging approximately 21 to 24 ribonucleotides in length. The major mode of action of miRNA is to bind to complimentary RNA sequences in the 3'-UTR of mRNA, and to thereby act as a repressor of that mRNA's expression $[7,8,10,33,38,41,51-56]$. Upregulated miRNAs are now generally accepted to predominantly act to decrease their target mRNA levels, and hence downregulate the genetic information encoded by that target mRNA [41,50-56]. Upregulated miRNAs and downregulated mRNAs may help explain the general downregulation of gene expression as is observed in the AD brain $[9,39,42,51,59]$. Of the approximately 2,000 human miRNAs currently known, only about 30 or 40 miRNAs are abundantly expressed in either the brain or the retina [51-56,59]. Figure 1 describes the expression of a small family of potentially pathogenic, NF-кB-regulated miRNAs that are significantly upregulated by a combinatorial cocktail of [IL-1 $\beta+A \beta 42]$ in human neuronal-glial (HNG) cells in a primary co-culture $[38,55,59]$. This represents a physiologically relevant induction as both IL-1 $\beta$ and A $\beta 42$ peptides are increased in abundance in AD brain [1-3,12$15,17,18]$. The upregulated miRNA results in Figure 1 have been independently confirmed using RT-PCR and/or Northern and or LED-Northern dot-blot techniques $[6,7,55-57,59]$. These same miRNAs have been observed to be upregulated in $\mathrm{AD}$ and in age-related macular degeneration, but not in unaffected anatomical regions of these same brain and retinal tissues $[7,8,38,43]$.

Common to aged, degenerating brain and retina are significant upregulation of miRNA-125b and miRNA$146 \mathrm{a}$, and their increases positively correlate with AD progression $[38,59]$. As discussed further below, upregulation of these miRNAs has been shown to be involved with a deficit in synaptic and neurotrophic signaling, synaptogenesis and the induction of amyloidogenesis and inflammatory signaling due to their selective targeting of several brain mRNA 3'-UTRs, including a critical downregulation of 15-lipoxygenase (15-LOX), synapsin-2 (SYN-2), IRAK-1, CFH and tetraspanin-12 (TSPAN12) gene expression [38,55,56,61-82]. Interestingly, the miRNA-mediated downregulation of certain brain mRNAs, and hence the impairment in their expression, contributes downstream to AD-relevant deficits. For example, the miRNA-146a-mediated downregulation of 


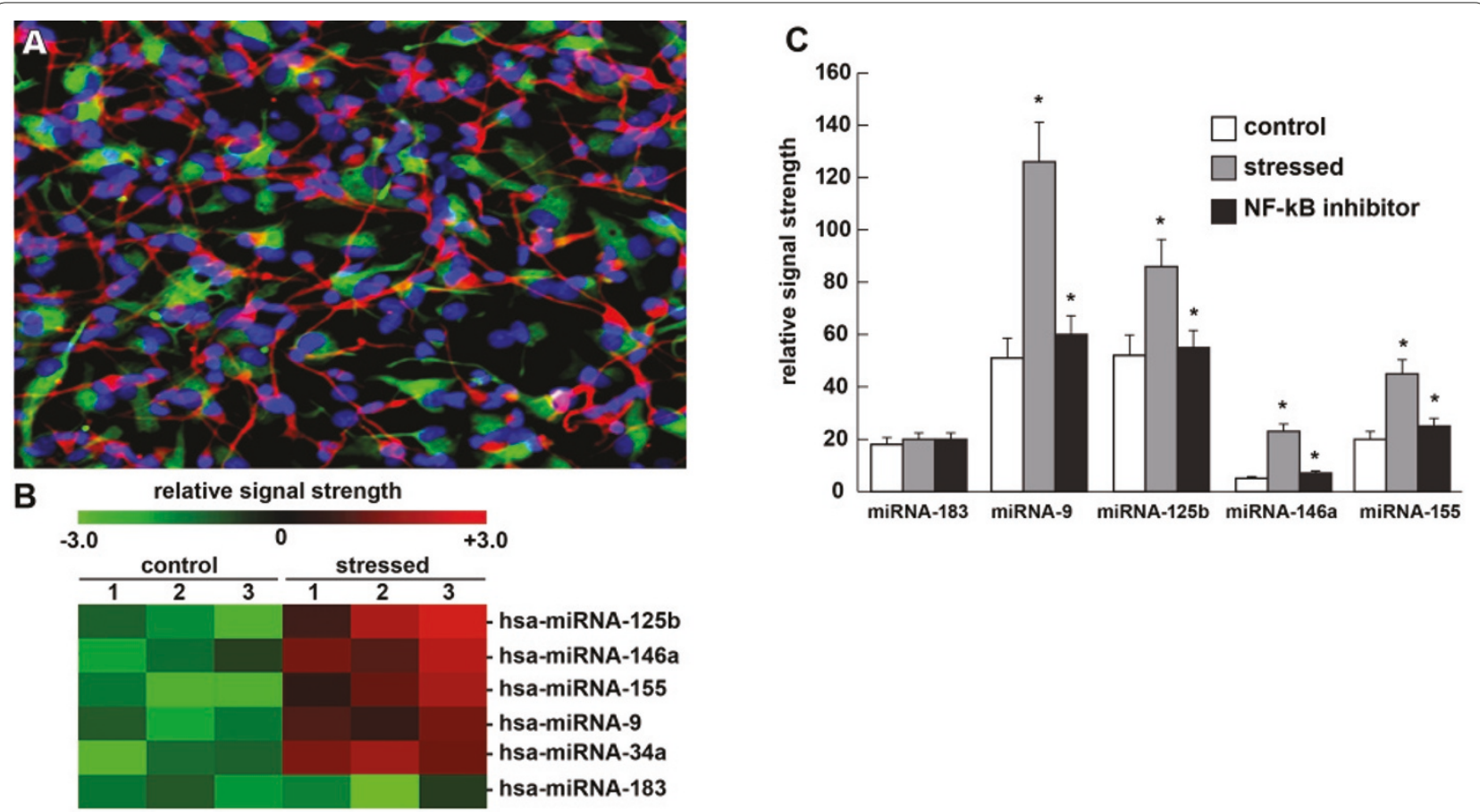

Figure 1. Expression of a small family of potentially pathogenic, NF-kB-regulated miRNAs. (A) Light microscopic photograph of human neuronal-glial (HNG) cells in primary culture stained with: antibody to glial fibrillary acidic protein, a glial-specific cytoplasmic marker (green fluorescence; $\lambda_{\max }=556 \mathrm{~nm}$ ); antibody to $\beta$ TUBIII, a neuron-specific cytoplasmic marker (red; $\lambda_{\max }=702 \mathrm{~nm}$ ); and Hoescht 33258 to highlight the morphological features of both glial cell and neuronal cell nuclei (blue; $\lambda_{\max }=461 \mathrm{~nm}$ ). Note: large nuclear area, relative to both glial or neuronal cytoplasmic area, is indicative of high levels of transcriptional activity $[10,52,55,102]$ (18 days in culture; 20x magnification) $[6,38,78]$. (B) miRNA array cluster analysis and heatmap data from [IL-1 $\beta+A \beta 42]$-induced HNG cells in primary culture; relative induction of homo sapien (hsa)-miRNA125b, hsa-miRNA-146a, hsa-miRNA-155, hsa-miRNA-9, hsa-miRNA-34a and hsa-miRNA-183 in control $(n=3)$ and stressed $(n=3)$ HNG cells by a cocktail of [LL-1 $\beta+A \beta 42]$ in combination [38,52,78]. Note: twofold to sixfold upregulation in miRNA-125b, miRNA-146a, miRNA-155, miRNA-9 and hsa-miRNA-34a and no significant change in hsa-miRNA-183 (control miRNA in the same sample). (C) [IL-1 $\beta+A \beta 42]$-induced HNG cells in primary culture $[38,78]$ show significant upregulation of hsa-miRNA-9, hsa-miRNA-125b, hsa-miRNA-146a, and miRNA-155 and quenching of their induction using the polyphenolic resveratrol analog CAY10512 (trans-3,5,4'-trihydroxystilbene). A $342+\mathrm{IL}-1 \beta$ has been previously shown to induce NF-KB and proinflammatory miRNA expression in several different human brain primary cell types $[38,53,72,78]$; other classes of NF-KB inhibitors, including the polyphenolic free radical scavenger curcumin and pyrrolidine dithiocarbamate, have also been shown to significantly quench the upregulation of inducible brain-enriched miRNAs indicating their NF-kB sensitivity $[38,72,78] . n=3$ to 5 ; ${ }^{*} P<0.01$ (analysis of variance), gray bars over white bars (upregulation) or black bars over gray bars (downregulation).

TSPAN12 impairs the disintegrin and metalloproteinase-10 activity, thus shunting $\beta$ APP processing activities into more amyloidogenic and proinflammatory $A \beta 42-$ generating pathways (Table 1) [1-5,80-82].

\section{AD-relevant effects of two NF-KB-regulated proinflammatory miRNAs}

Table 1 displays some of the integrated neurobiological effects of just two of the most consistently upregulated NF-кB-induced miRNAs in AD brain and in stressed HNG cells in primary culture: miRNA-125b and miRNA146a. Several of their multiple AD-relevant mRNA targets, the function of those mRNAs and consequences of their deficits, and original key references are shown.

As indicated, inducible miRNA-125b and miRNA-146a have experimentally verified mRNA targets including the glial cell cycle and glial cell proliferation inhibitor cyclin-dependent kinase 2A (CDKN2A), the neurotransmitter release and synaptic protein SYN-2, the essential docosahexaenoic acid-to-neuroprotectin D1 (NPD1) conversion enzyme 15-LOX (also known as ALOX15), the innate immune system regulator $\mathrm{CFH}$, IRAK-1 and the $\beta \mathrm{APP}-$ disintegrin and metalloproteinase-10 regulatory protein TSPAN12 [3,57-82]. These combined data suggest a complex and highly interactive role for NF- $\mathrm{kB}$, miRNA-125b and miRNA-146a in physiologically stressed HNG cells in primary co-culture. Remarkably, the misregulation of just two NF-кB-regulated, proinflammatory miRNAs has the potential to contribute to the deregulation of several key features of $\mathrm{AD}$ neuropathology, including neurotrophic support, synaptogenesis, neuroinflammation, innate immune signaling, and amyloidogenesis in primary human neural cells. Importantly, upregulation of miRNA-125b 
Table 1. An NF-kB-activated miRNA-mediated proinflammatory genetic network in Alzheimer's disease

\begin{tabular}{|c|c|c|c|c|}
\hline Human miRNA & mRNA target & mRNA function & Result of mRNA or gene expression deficit & References \\
\hline miRNA-125b & CDKN2A & $\begin{array}{l}\text { Cyclin-dependent kinase inhibitor } 2 \mathrm{~A} \text { cell cycle } \\
\text { inhibitor; induces cell cycle arrest }\end{array}$ & $\begin{array}{l}\text { Downregulation of cell cycle control: glial } \\
\text { cell proliferation }\end{array}$ & [57-60] \\
\hline miRNA-125b & SYN-2 & $\begin{array}{l}\text { Synapsin-2: neuronal synaptic phosphor- } \\
\text { protein; coats synaptic vesicles; functions in } \\
\text { the regulation of neurotransmitter release }\end{array}$ & $\begin{array}{l}\text { Impairment of neurotransmitter release; } \\
\text { synaptic signaling deficits }\end{array}$ & {$[2,3,61-65]$} \\
\hline miRNA-125b & 15-LOX-1 & $\begin{array}{l}\text { ALOX15; arachidonate 15-lipoxygenase; } \\
\text { essential in the conversion of docosahexaenoic } \\
\text { acid to neuroprotectin D1 (NPD1) }\end{array}$ & $\begin{array}{l}\text { Deficit in neurotrophic omega-3 fatty acid } \\
\text { derivatives in the brain }\end{array}$ & {$[3,66-69]$} \\
\hline miRNA-146a & $\mathrm{CFH}$ & $\begin{array}{l}\text { Complement factor } \mathrm{H} \text {; repressor of activation } \\
\text { of the innate immune response in brain and } \\
\text { retina at the } \mathrm{C} 3 \text { to } \mathrm{C} 3 \mathrm{~b} \text { transition; deficits in } \\
\text { disease are proinflammatory }\end{array}$ & $\begin{array}{l}\text { Defect in control of the innate immune } \\
\text { response; chronic stimulation of the innate } \\
\text { immune response and proinflammatory } \\
\text { signaling }\end{array}$ & {$[2,3,8,70-75]$} \\
\hline miRNA-146a & IRAK-1 & $\begin{array}{l}\text { Interleukin-1 receptor-associated kinase 1; } \\
\text { initiation of the innate immune response and } \\
\text { NF-KB signaling }\end{array}$ & $\begin{array}{l}\text { Compensatory surge in IRAK-2 and chronic } \\
\text { stimulation of NF-KB signaling in the brain }\end{array}$ & {$[3,76-79]$} \\
\hline miRNA-146a & TSPAN12 & $\begin{array}{l}\text { Transmembrane } 4 \text { superfamily member } \\
\text { 12; regulator of cell surface receptor signal } \\
\text { transduction; activates ADAM10-dependent } \\
\text { cleavage activity of } \beta \text { APP }\end{array}$ & $\begin{array}{l}\text { Results in a shift from neurotrophic (sAPPa) } \\
\text { to amyloidogenic (Aß42 peptide) processing } \\
\text { of } \beta A P P\end{array}$ & {$[3,80-83]$} \\
\hline
\end{tabular}

Both miRNA-125b and miRNA-146a target the 3'-UTR of several Alzheimer's disease (AD)-relevant mRNAs; these have been predicted using bioinformatics and confirmed experimentally using multiple analytical approaches including DNA arrays, RT-PCR, Northern and LED-Northern dot blots, and western and ELISA analysis $[2,3,6-10,38,51-57,78]$. Additional and original references are provided here and in the text. Factors that induce NF-kB such as HSV-1 and aluminum also induce the expression of proinflammatory miRNAs such as miRNA-125b and miRNA-146a $[73,83,86,88,101,102,106,107,110]$. Overexpression of just two NF-KB-regulated miRNAs (miRNA-125b and miRNA-146a) may in part explain many of the observed pathogenic features of AD including glial cell proliferation, synaptic signaling and neurotrophic deficits, chronic overstimulation of NF-KB and innate immune signaling and proinflammatory amyloidogenesis [8,59]. The mRNA targets for miRNA-9, miRNA-34a and miRNA-155 (Figure 1) and other inducible miRNAs, and their possible contribution to alterations in gene expression in AD, are currently under intensive research investigation by multiple research laboratories. ADAM10, a disintegrin and metalloproteinase-10; $\beta$ APP, $\beta$-amyloid precursor protein; TSPAN12, tetraspanin-12.

and miRNA-146a has been observed in anatomical areas of the brain targeted by the AD process, but neither in unaffected regions of the same brain, such as the brain stem or thalamus, nor in the same anatomical areas in healthy age-matched controls $[57,74,83]$.

More recently, interrelated and independent studies further suggest the sensitivity of human miRNA-9, miRNA-34a and miRNA-155 to AD-relevant stress and neuropathology as NF-кB-mediated miRNAs (Figure 1) $[38,40,45,59,74,83]$. While the neurological activities of miRNA-9, miRNA-34a and miRNA-155 are currently under active investigation by multiple laboratories, miRNA-125b and miRNA-146a and several of their mRNA targets, and the implications, are further discussed in the following sections.

\section{miRNA-125b}

One of the most human brain cell-abundant miRNAs, if not the most abundant CNS miRNA, is inducible miRNA-125b [23,45,49,51,55,57,58,83-87]. This extensively studied 22-nucleotide miRNA (encoded at human chromosome 11q24.1: 5'-ucccugagacccuaacuuguga-3' [Genbank:NR_029671.1]) was first shown to be upregulated in both stressed and differentiating mouse and human neurons, and has since been implicated in mammalian neuronal development, brain cell signaling functions and degenerative disease $[45,49]$.

NF-кB-regulated proinflammatory miRNA-125b has been further shown to be induced by human neurotrophic viruses and by neurotoxic metal sulfates, such as aluminum sulfate, that generate robust oxidative stress and ROS in human brain cells [83-101]. The high-abundance miRNA-125b is also associated with brain cancers, where it apparently also targets CDKN2A, a negative regulator of astroglial cell growth and proliferation [57-59]. Consistent upregulation of miRNA-125b, and CDKN2A downregulation, thus associates with deregulated astroglial cell proliferation, and is thereby linked to the proliferation of astroglia in several diverse neurodegenerative conditions including AD, Down's syndrome and epileptogenesis, and in inflammatory glial cell proliferation in glioma and glioblastoma multiforme $[57,58,83,86,87,97-110]$. Indeed, the capability of miRNA$125 \mathrm{~b}$ in simultaneously regulating multiple downstream pathogenic gene targets may play a key role in explaining the complex multigenetic mechanisms underlying glioblastoma multiforme, an aggressive grade IV astrocytoma with a 1-year median survival rate and dismal prognosis despite current treatment modalities $[57,58]$. 
Interestingly, the pathogenic upregulation of miRNA$125 \mathrm{~b}$ can be effectively quenched using both anti-NF-кB and anti-miRNA-125b intervention strategies (Figure 1) $[51,57,74,83]$.

\section{miRNA-146a}

miRNA-146a (chromosome 5q34; 5'-gagaacugaauuccauggguu-3' [Genbank:NR_029701.1]) was first described as an NF-KB-regulated proinflammatory miRNA that was found to target signaling proteins of innate immune responses, and more specifically the 3'-UTR of CFH in murine monocytes [70-72,75]. Subsequently, elevated miRNA-146a has also been shown to target human CFH and IRAK-1 in AD brain, and the role of miRNA-146a in altered innate immune responses and neuroinflammation signaling in progressively degenerating human brain cells and tissues is well documented [10,38,53,56,72,101]. Interestingly, although $\mathrm{CFH}$ is a highly abundant human serum protein of hepatic origin, abundant $\mathrm{CFH}$ presence in brain and retinal tissues suggests $\mathrm{CFH}$ involvement in the innate immune response and inflammatory regulation within the privileged immunology of these tissues [71-79].

Although miRNA-146a is a much less basally abundant miRNA when compared with miRNA-125b, it has been found to be the most inducible and upregulated miRNA in $\mathrm{AD}$ brain compared with all other NF-KB-regulated species so far indentified (Figure 1 and Table 1). The reason why miRNA-146a is one of the most rapidly induced of all brain miRNAs may be due to the presence of three cannonical tandem NF-кB binding sites in the pre-miRNA-146a promoter located at chromosome 5q34 $[38,70,78]$. Disease-related upregulation of miRNA-146a has also been observed in human prion disease and in inflammatory processes associated with epilepsy, but no increase in miRNA-146a has been associated with multiple sclerosis, Huntington's disease, schizophrenia, and in certain grades of glioblastoma where the actions of other upregulated miRNAs may predominate [84-86].

miRNA-125b and miRNA-146a mRNA targets in the brain As indicated in Table 1, upregulation in brain-abundant miRNA-125b is associated with downregulation of the cell cycle inhibitor CDKN2A and glial cell proliferation, a pathological feature of $\mathrm{AD}$ gliosis, glioma and glioblastoma $[57,58,72]$. Upregulated miRNA-126b also downregulates the synaptic vesicle-associated neuronalenriched phosphoprotein (which associates with the cytoplasmic surface of synaptic vesicles) and neurotransmitter release regulator SYN-2 [61-65], as well as the 15-LOX enzyme essential for the conversion of the essential omega-3 fatty acid docosahexaenoic acid into the potent docosahexaenoic acid derivative and neuroprotectant NPD1 [66-69]. Deficits in 15-LOX correlate with NPD1 deficits in AD brain [66-68]. Similarly, a miRNA-146a-regulated $\mathrm{CFH}$ is a key negative regulator of the innate immune system, and miRNA-146a upregulation associates with decreased $\mathrm{CFH}$ and a chronic inflammatory neural degeneration $[38,53,56,87]$.

Similarly, the mRNA encoding the four-time membrane spanning integral membrane protein TSPAN12 is also a target for miRNA-146a, and upregulated miRNA146 a contributes to the downregulation of TSPAN12 as is observed in $\mathrm{AD}$ brain and in cytokine and $\mathrm{A} \beta$ peptidestressed human brain cells $[8,80,81]$. Just as sufficient TSPAN12 appears to be required for the neurotrophic cleavage of the $\beta A P P$, insufficient TSPAN12 is associated with the induction of amyloidogenesis $[8,80,81]$.

The integrated miRNA-mRNA interactions of as few as two human brain miRNAs (miRNA-125b and miRNA146a) may hence in part explain not only the observed downregulation of CDKN2A, 15-LOX, SYN-2, CFH, IRAK-1 and TSPAN12, but also progressive, pathogenic deficiencies in innate and immune signaling, neurotrophic support, and synaptogenesis and amyloidogenesis in the AD brain.

\section{Extraneural and environmental factors that are strong inducers of NF-кB-mediated and miRNA-mediated proinflammatory signaling} Herpes simplex virus 1

While only about $5 \%$ of all AD cases are genetic and $95 \%$ of all AD cases are of sporadic (idiopathic, or unknown) origin, a significant epigenetic contributor to sporadic $\mathrm{AD}$ may well be of extraneural or environmental origin [1-3]. Two independent factors that have long been thought to contribute to inflammatory aspects of $\mathrm{AD}$ are neurotropic viral infection, specifically by HSV-1, and the abundant neurotoxin aluminum in the environment [88-108].

About $95 \%$ of all humans harbor HSV-1 in various CNS compartments, and normally $\mathrm{HSV}-1$ remains latent until activated by a number of factors including stress, radiation, trauma or ancillary neurological disease [88-92]. For at least 30 years, HSV-1 activation or previous HSV-1 infection of the human CNS has been associated with increased risk for $\mathrm{AD}$, and the appearance of $\mathrm{AD}$-relevant neuropathological lesions [88-96]. Interestingly, HSV-1 particles are associated with mature senile plaques in $\mathrm{AD}$ brain. HSV-1 and experimental infection of HNG cells in primary culture with HSV-1 significantly upregulate both NF- $\mathrm{KB}$ and miRNA-146a and a proinflammatory gene expression program. This upregulation culminates in neuronal blebbing and swelling, inflammation and ultimately brain cell death [88-95].

Treatment of AD with antiviral agents - such as the already US Food and Drug Administration-approved acyclovir (brand name Zovirax; GlaxoSmithKline, 
London, UK), penciclovir, valacyclovir (brand name Valtrex; GlaxoSmithKline) or foscarnet - has been suggested as a possible efficacious or adjunct treatment for AD [94-96] (unpublished observations). The pharmacological strategy here is that HSV-1 infection in the brain induces the accumulation of key pathogenic proteins, such as A 342 peptides, abnormally phosphorylated tau, and proinflammatory miRNAs, and that these antiviral agents have been shown to greatly reduce the abundance of A $\beta 42$ peptides, phosphorylated tau and proinflammatory miRNA-146a accumulation in human brain cells previously infected with HSV-1 [73,88,94-96].

\section{Aluminum}

Aluminum exists in the biosphere as the third most abundant element (after oxygen and silicon) and the first most abundant metal, and hence environmental exposure to aluminum is naturally quite extensive [97-109]. Additional biologically-relevant sources of aluminum come from drinking water, vaccines, medicines, beverages and food $[98,100]$. A considerable amount of work has been done on studying the effect of environmental toxins such as aluminum hydroxide and aluminum sulfate on NF-kB induction, on miRNA generation, speciation and complexity, and on the effects of aluminum on the pathogenic regulation of $\mathrm{AD}$-relevant gene expression [98,102-107].

Interestingly, aluminum potassium sulfate, or alum (hydrated potassium alum is $\operatorname{AlK}\left(\mathrm{SO}_{4}\right)_{2} \bullet 12 \mathrm{H}_{2} \mathrm{O}$ ), which is added to water-purification systems worldwide to clarify turbid drinking water, or aluminum hydroxide, used as an adjuvant to stimulate a local inflammatory response during vaccine injection, also strongly induce NF-кB, miRNA-146a, and a proinflammatory gene expression program in human primary brain cell models $[103,106,107]$. In fact, the capability of aluminum - an extremely high charge-density trivalent cation $\left(Z^{2} / r=18\right.$, where $Z$ is an unchanging charge of +3 and $r$ is the ionic radius of $0.5 \mathrm{~nm}$ ) - to crosslink and aggregate biological material is second to none in the realm of biosphere-available neurological metallotoxins [98-108].

Aluminum has also been shown to aggregate A $\beta 42$ peptides into a much more neurotoxic, immunogenic and proinflammatory fibrillar form, as observed within the end-stage senile plaques in advanced $\mathrm{AD}$ brain $[98,100]$. For example, when tested for the ability to induce ROS and NF-KB activation in vitro, comparison of aluminum, cadmium, copper, iron, mercury, gallium, magnesium, manganese, nickel, lead, tin or zinc (as sulfates) at $50 \mathrm{nmol}$ concentrations in HNG cell cocultures (using the novel, mixed isomer, fluorescent indicator 5-(and-6)-carboxy-2,7'-dichlorofluorescein diacetate) found aluminum to have by far the strongest ROS-inducing, NF-кB-inducing and inflammatory gene expression-inducing capacity of any trace metal tested $[10,109,110]$.

While antiviral therapeutic strategies have been advocated for the clinical treatment of $\mathrm{AD}[94,95]$, a single clinical trial using the actinobacterial siderophore desferrioxamine (mesylate) as an anti-oxidant, ROS scavenger and aluminum chelator has proved to be one of the most efficacious treatments yet for mild-to-severe AD [105-107]. This is also in line with the idea that drugs such as desferrioxamine (mesylate) and posiphen that target multiple pathogenic molecules or processes in AD brain may hold the best promise in the clinical management of this complex and multifactorial neurological disorder [1-5,105,108].

\section{Anti-miRNA (antagomir) strategies}

Using perfectly complimentary ribonucleotide anti-sense (anti-miRNA; antagomir) sequences to lower the ambient abundance of upregulated miRNA in the brain is a logical approach to neutralizing the pathogenic gene expression effects of some overly expressed miRNAs, and attenuating their effects on selective mRNA abundance. This neutralization has been demonstrated in primary human brain cell tissue co-culture for both miRNA-125b and miRNA-146a $[38,75,78,79,83,84]$. The structure of these small, single-stranded therapeutic anti-miRNAs can be chemically modified to increase their stability within the cell in vitro, and as little as 5 nM locked nucleic acidstabilized anti-miRNA per million human brain cells in primary tissue culture has been shown to have a dramatic quenching effect on both the target miRNA and proinflammatory gene expression induction patterns when analyzed using DNA and miRNA arrays and LEDNorthern analytical techniques $[6,7,55,75,79]$.

While it is not at the present time clear whether these anti-miRNA strategies can be translated into human therapies for inflammatory degeneration, these kinds of RNA silencing approaches have shown recent promise in the treatment of glioblastoma, the most lethal form of primary malignant tumor in the human CNS [58,83-85].

\section{Conclusion}

The six main conclusions from the research work presented in this review are as follows: the miRNAmediated downregulated expression of several bioinformatics and experimentally confirmed mRNAs are targeted by increases in $\mathrm{AD}$ brain-relevant miRNA; stressors known to induce NF-kB also transactivate specific NF-кB-sensitive brain cell miRNAs; single miRNAs, such as miRNA-125b and miRNA-146a, have the potential to regulate multiple mRNA abundances relevant to the AD process; epigenetic and environmental factors such as HSV-1 infection and bioavailable aluminum may be highly relevant to the AD process, as 
they are both exceedingly strong inducers of NF-KB and proinflammatory miRNAs; specific antiviral, trivalent metal chelation, NF- $\mathrm{KB}$ inhibitors, or anti-miRNA strategies may be able to quench pathogenic miRNA overabundance and restore homeostasis to the AD brain, as is seen in models of AD in vitro; and HNG cells in primary co-culture are a proven, reliable, and human brain disease-relevant in vitro cell model to study the mechanism of transcription factor-mediated miRNA activation and speciation, and inflammatory signaling under normal aging, and physiologically relevant stress conditions.

Whether these mechanisms are operative in $\mathrm{Tg}-\mathrm{AD}$ murine models, whether antiviral, anti-aluminum, antiNF- $\mathrm{kB}$ or anti-miRNA strategies operate mechanistically in the same way in Tg-AD or cell culture models, or whether Tg-AD results can be extrapolated into human clinical trials are currently not known, and are all very active areas of independent research investigation. Since multiple mRNA targets are known to associate with neurodegenerative disease, and participate in complex positive or negative NF-KB-mediated feedback and signaling loops, these miRNA-mRNA linkage studies and their functional interpretations in disease may be more complex than initially anticipated, especially when multiple epigenetic or environmental factors are involved [87-111]. Importantly, the significant overabundance of NF- $\mathrm{KB}$ and miRNA in specific anatomical regions in AD neocortex and hippocampus strongly implicates an NF-кB-mediated, miRNA-regulated inflammatory disease mechanism that appears to selectively downregulate different pathology-associated brain gene transcripts during the sporadic $\mathrm{AD}$ process, including those AD-relevant miRNA-mRNA pairings and the pathogenic consequences depicted in Table $1[38,78]$.

In summary, AD is a complex neurodegenerative disease caused by the dysregulation of numerous brain cell functions and multiple neurobiological networks [1-3,5,34-37,109-114]. A wiser therapeutic strategy may therefore be to consider the use of drugs or drug combinations that have multiple pathogenic targets, with minimal off-target and negligible peripheral toxic effects [1-7,32,109-114]. These effects include the implementation of novel drug delivery systems [111-114]. As an important step to achieve this goal we currently need to better understand the role of brain chromatin-mediated transcription mechanisms in $\mathrm{AD}$ and how these compare with normally aging brain, to better understand the role of ancillary DNA-binding proteins and proinflammatory transcription factors such as NF- $\mathrm{KB}$ in these processes, and to better understand features of other related epigenetic mechanisms on specific miRNA-mRNA recognition, activation, and signaling pathways. Yet another layer of miRNA-mediated genetic complexity in the brain appears to be the role of miRNA nucleases and the relatively rapid turnover of specific miRNAs, which ultimately modulates the ability of miRNAs to impact pathogenic signaling $[38,78,87,115,116]$. Paradoxically, certain inflammatory responses may prove to be neuroprotective or beneficial, so it will be important to quantify both the individual contribution, and integration, of each of these proinflammatory signaling pathways to the $A D$ process. Eventually, their net impact on the neurogenetics of brain cell function in healthy aging and in inflammatory neurodegenerative disease will be elucidated, yielding advanced therapeutic strategies and combinatorial approaches that have not yet been considered.

\section{Abbreviations}

$A \beta, \beta$-amyloid; AD, Alzheimer's disease; $\beta A P P, \beta$-amyloid precursor protein; CDKN2A, cyclin-dependent kinase inhibitor $2 A ; C F H$, complement factor $H_{\text {; }}$ CNS, central nervous system; ELISA, enzyme-linked immunosorbent assay; HNG, human neuronal-glial; HSV-1, herpes simplex virus 1; IL, interleukin; IRAK, IL-1 receptor-associated kinase; 15-LOX, 15-lipoxygenase; miRNA, microRNA; $N F$, nuclear factor; NPD1, neuroprotectin D1 PCR, polymerase chain reaction; $\mathrm{ROS}$, reactive oxygen species; RT, reverse transcription; SYN-2, synapsin-2; $\mathrm{Tg}-\mathrm{AD}$, transgenic AD (murine model for disease); TNF, tissue necrosis factor: TSPAN12, tetraspanin-12; UTR, untranslated region.

\section{Competing Interests}

The author declares that he has no competing interests.

\section{Acknowledgements}

This research was presented in part at the 12th annual Alzheimer's Association International Conference (AAIC12) in Vancouver, British Columbia, Canada, 14-19 July 2012. Thanks are extended to Dr Yuhai Zhao, Dr Surjyadipta Bhattacharjee, Dr Brandon M Jones and Dr Darlene Guillot for expert technical assistance, the co-culture of primary HNG cells, unpublished data, recent publications in this research area and helpful interpretative discussions, and to $\operatorname{Dr} C$ Eicken, $\operatorname{Dr} C$ Hebel and Dr P Dua for the miRNA array work and initial data interpretation. Human brain tissues were provided in part by the Harvard Brain Tissue Bank, the Oregon State University Health Science Centre, the Louisiana State University Health Sciences Center Brain Bank, and by the Memory Impairments and Neurological Disorders Institute at the University of California, Irvine Alzheimer's Disease Research Center (funded in part though NIA P50 AG16573). Thanks are also extended to the physicians, neuropathologists and families who have kindly provided human brain and retinal tissues for research purposes. Research on the structure and function of NF-KB and miRNA expression, speciation and complexity in AD brain and related neurological disorders in the Lukiw laboratory were supported through Grant Number P20RR016456 from the National Center for Research Resources, Translational Research Initiative Grants from LSU Health Sciences Center New Orleans (WJL), Alzheimer Association Investigator-Initiated Research Grant IIRG-09-131729 (WJL), and NIH NIA Grants AG18031 and AG038834 (WJL). The content of this manuscript is solely the responsibility of the author and does not necessarily represent the official views of the National Institute on Aging, National Center for Research Resources, or the National Institutes of Health.

Published: 6 December 2012

\section{References}

1. Hardy J: A hundred years of Alzheimer's disease research. Neuron 2006, 52:3-13.

2. Lukiw WJ: 100 years of $A D$ research; are we any closer to a cure? Aging Health 2007, 3:279-282.

3. Lukiw WJ: Amyloid beta (A $\mathrm{B}$ ) peptide modulators and other current treatment strategies for Alzheimer's disease (AD). Expert Opin Emerg Drugs 2012. [Epub ahead of print]

4. Maccecchini ML, Chang MY, Pan C, John V, Zetterberg H, Greig NH: Posiphen as a candidate drug to lower CSF amyloid precursor protein, amyloid- $\beta$ 
peptide and s levels: target engagement, tolerability and pharmacokinetics in humans. J Neurol Neurosurg Psychiatry 2012, 83:894-902.

5. Eikelenboom P, Hoozemans JJ, Veerhuis R, van Exel E, Rozemuller AJ, van Gool WA: Whether, when and how chronic inflammation increases the risk of developing late-onset Alzheimer's disease. Alzheimers Res Ther 2012, 4:15-26.

6. Zhao Y, Cui JG, Lukiw WJ: Natural secretory products of human neural and microvessel endothelial cells: implications in pathogenic 'spreading' and Alzheimer's disease. Mol Neurobiol 2006, 34:181-192.

7. Lukiw WJ, Alexandrov PN, Zhao Y, Hill JM, Bhattacharjee S: Spreading of Alzheimer's disease inflammatory signaling through soluble micro-RNA. Neuroreport 2012, 23:621-626.

8. Lukiw WJ, Alexandrov PN: Regulation of complement factor H (CFH) by multiple miRNAs in Alzheimer's dsease (AD) brain. Mol Neurobiol 2012, 46:11-19.

9. Lukiw WJ, Bazan NG: Inflammatory, apoptotic, and survival gene signaling in Alzheimer's disease. A review on the bioactivity of neuroprotectin D1 and apoptosis. Mol Neurobiol 2010, 42:10-16

10. Pogue Al, Li YY, Cui JG, Zhao Y, Kruck TP, Percy ME, Tarr MA, Lukiw WJ: Characterization of an NF-KB-regulated, miRNA-146a-mediated downregulation of complement factor $\mathrm{H}$ (CFH) in metal-sulfate-stressed human brain cells. J Inorg Biochem 2009, 103:1591-1595.

11. Katselson EN: Alzheimer's disease simulating an abscess of the left temporal lobe of the brain in a patient with chronic suppurative inflammation of the left middle ear. Zh Ushn Nos Gorl Bolezn 1968, 28:95-96.

12. Eikelenboom P, Zhan SS, van Gool WA, Allsop D: Inflammatory mechanisms in Alzheimer's disease. Trends Pharmacol Sci 1994, 15:447-450.

13. Aisen PS, Davis KL: Inflammatory mechanisms in Alzheimer's disease: implications for therapy. Am J Psychiatry 1994, 151:1105-1113.

14. NIH Medline Search; Keywords'Inflammation, Alzheimer's Disease' [http:// www.ncbi.nlm.nih.gov/gquery/?term=inflammation\%20 alzheimer\%275\%20disease]

15. Verri M, Pastoris O, Dossena M, Aquilani R, Guerriero F, Cuzzoni G, Venturini L, Ricevuti G, Bongiorno Al: Mitochondrial alterations, oxidative stress and neuroinflammation in Alzheimer's disease. Int I Immunopathol Pharmacol 2012, 25:345-353.

16. Wojtera M, Sobów T, Kłoszewska I, Liberski PP, Brown DR, Sikorska B: Expression of immunohistochemical markers on microglia in CreutzfeldtJakob disease and Alzheimer's disease: morphometric study and review of the literature. Folia Neuropathol 2012, 50:74-84

17. Wilcock DM: Neuroinflammation in the aging down syndrome brain: lessons from Alzheimer's disease. Curr Gerontol Geriatr Res 2012, 2012:170276.

18. Povova J, Ambroz P, Bar M, Pavukova V, Sery O, Tomaskova H, Janout V: Epidemiological of and risk factors for Alzheimer's disease. Biomed Pap Med Fac Univ Palacky Olomouc Czech Repub 2012, 156:108-114.

19. Alzheimer A, Stelzmann RA, Schnitzlein HN, Murtagh FR: An English translation of Alzheimer's 1907 paper 'Uber eine eigenartige Erkankung der Hirnrinde.' Clin Anat 1995, 8:429-431.

20. Hardy J: Alzheimer's disease: the amyloid cascade hypothesis: an update and reappraisal. J Alzheimers Dis 2006, 9:151-153.

21. Selkoe DJ: Resolving controversies on the path to Alzheimer's therapeutics. Nat Med 2011, 17:1060-1065.

22. Esiri MM: Chance SA: Vulnerability to Alzheimer's pathology in neocortex: the roles of plasticity and columnar organization. J Alzheimers Dis 2006, 9:79-89.

23. Cui JG, Hill JM, Zhao Y, Lukiw WJ: Expression of inflammatory genes in the primary visual cortex of late-stage Alzheimer's disease. Neuroreport 2007, 18:115-119.

24. van de Pol LA, Korf ES, van der Flier WM, Brashear HR, Fox NC, Barkhof F, Scheltens P: Magnetic resonance imaging predictors of cognition in mild cognitive impairment. Arch Neurol 2007, 64:1023-1028.

25. Marshall GA, Monserratt L, Harwood D, Mandelkern M, Cummings JL, Sultzer $\mathrm{DL}$, Laforce R Jr, Rabinovici GD: Amyloid imaging in the differential diagnosis of dementia: review and potential clinical applications. Alzheimers Res Ther 2011, 3:31-34.

26. Velliquette RA, O'Connor T, Vassar R: Energy inhibition elevates betasecretase levels and activity and is potentially amyloidogenic in APP transgenic mice: possible early events in Alzheimer's disease pathogenesis. J Neurosci 2005, 25:10874-10883.
27. Ewers M, Sperling RA, Klunk WE, Weiner MW, Hampel H: Neuroimaging markers for the prediction and early diagnosis of Alzheimer's disease dementia. Trends Neurosci 2011, 34:430-442

28. Siemers ER, Quinn JF, Kaye J, Farlow MR, Porsteinsson A, Tariot P, Zoulnouni P, Galvin JE, Holtzman DM, Knopman DS, Satterwhite J, Gonzales C, Dean RA, May PC: Effects of a gamma-secretase inhibitor in a randomized study of patients with Alzheimer disease. Neurology 2006, 66:602-604.

29. Tomita T: At the frontline of Alzheimer's disease treatment: gammasecretase inhibitor/modulator mechanism. Naunyn Schmiedebergs Arch Pharmacol 2008, 377:295-300

30. Siemers ER, Dean RA, Friedrich S, Ferguson-Sells L, Gonzales C, Farlow MR, May PC: Safety, tolerability, and effects on plasma and cerebrospinal fluid amyloid-beta after inhibition of gamma-secretase. Clin Neuropharmacol 2007, 30:317-325.

31. Epis R, Marcello E, Gardoni F, Luca MD: Alpha, beta-and gamma-secretases in Alzheimer's disease. Front Biosci (Schol Ed) 2012, 4:1126-1150.

32. Van Broeck B, Van Broeckhoven C, Kumar-Singh S: Current insights into molecular mechanisms of Alzheimer disease and their implications for therapeutic approaches. Neurodegener Dis 2007, 4:349-365

33. Veremeyko T, Starossom SC, Weiner HL, Ponomarev ED: Detection of miRNAs in microglia by real-time PCR in normal CNS and during neuroinflammation. J Vis Exp 2012, 23:65-71.

34. Hickman SE, El Khoury J: The neuroimmune system in Alzheimer's disease: the glass is half full. J Alzheimers Dis 2012. [Epub ahead of print]

35. Lai AY, McLaurin J: Clearance of amyloid- $\beta$ peptides by microglia and macrophages: the issue of what, when and where. Future Neurol 2012, 7:165-176

36. Varnum MM, IkezUT: The classification of microglial activation phenotypes on neurodegeneration and regeneration in Alzheimer's disease brain. Arch Immunol Ther Exp (Warsz) 2012, 60:251-266.

37. Tan B, Choi RH, Chin TJ, Kaur C, Ling EA: Manipulation of microglial activity as a therapy for Alzheimer's disease. Front Biosci (Schol Ed) 2012, 4:1402-1412.

38. Lukiw WJ, Zhao Y, Cui JG: An NF-kB-sensitive micro RNA-146a-mediated inflammatory circuit in Alzheimer disease and in stressed human brain cells. J Biol Chem 2008, 283:31315-31322.

39. Rubio-Perez JM, Morillas-Ruiz JM: A review: inflammatory process in Alzheimer's disease, role of cytokines. Sci World J 2012, 2012:756357.

40. Sen R: The origins of NF-KB. Nat Immunol 2011, 12:686-688.

41. Boldin MP, Baltimore D: MicroRNAs, new effectors and regulators of NF-KB Immunol Rev 2012, 246:205-220.

42. Lukiw WJ, Bazan NG: Strong NF-kB-DNA binding parallels cyclooxygenase-2 gene transcription in aging and in sporadic Alzheimer's disease superior temporal lobe neocortex. J Neurosci Res 1998, 53:583-592.

43. Lukiw WJ, Ottlecz A, Lambrou G, Grueninger M, Finley J, Thompson HW, Bazan NG: Coordinate activation of HIF-1 and NF-KB DNA binding and COX-2 and VEGF expression in retinal cells by hypoxia. Invest Ophthalmol Vis Sci 2003, 44:4163-4170.

44. Cai D, Liu T: Inflammatory cause of metabolic syndrome via brain stress and NF-KB. Aging (Albany NY) 2012, 4:98-115.

45. Smale ST: Hierarchies of NF-KB target-gene regulation. Nat Immunol 2011, 12:689-694.

46. Harari OA, Liao JK: NF-KB and innate immunity in ischemic stroke. Ann NY Acad Sci 2010, 1207:32-40

47. Cai D: NF-KB-mediated metabolic inflammation in peripheral tissues versus central nervous system. Cell Cycle 2009, 8:2542-2548.

48. Granic I, Dolga AM, Nijholt IM, van Dijk G, Eisel UL: Inflammation and NF-KB in Alzheimer's disease and diabetes. J Alzheimers Dis 2009, 16:809-821.

49. Cui JG, Li YY, Zhao Y, Bhattacharjee S, Lukiw WJ: Differential regulation of interleukin-1 receptor-associated kinase-1 (IRAK-1) and IRAK-2 by microRNA-146a and NF-KB in stressed human astroglial cells and in Alzheimer disease. J Biol Chem 2010, 285:38951-38960.

50. Lukiw WJ, Handley P, Wong L, McLachlan DRC: BC200 and other small RNAs in normal human neocortex, non-Alzheimer dementia (NAD), and senile dementia of the Alzheimer type (AD). Neurochem Res 1992, 17:591-597.

51. Lukiw WJ: Micro-RNA speciation in fetal, adult and Alzheimer's disease hippocampus. Neuroreport 2007, 18:297-300.

52. Bartel DP: MicroRNAs: target recognition and regulatory functions. Cell 2009, 136:215-233

53. Li L, Chen XP, Li YJ: MicroRNA-146a and human disease. Scand I Immunol 2010, 71:227-231. 
54. Guo H, Ingolia NT, Weissman JS, Bartel DP: Mammalian miRNAs act to decrease target mRNA levels. Nature 2010, 466:835-840.

55. Cui JG, Hill JM, Zhao Y, Lukiw WJ: Expression of inflammatory genes in the primary visual cortex of late-stage Alzheimer's disease. Neuroreport 2007, 18:115-119.

56. Lukiw WJ, Dua P, Pogue Al, Eicken C, Hill JM: Up-regulation of micro RNA146a (miRNA-146a), a marker for inflammatory neurodegeneration, in sporadic Creutzfeldt-Jakob disease (sCJD) and Gerstmann-Straussler Scheinker (GSS) syndrome. J Toxicol Environ Health 2011, 74:1460-1468.

57. Pogue Al, Cui JG, Li YY, Zhao Y, Culicchia F, Lukiw WJ: miRNA-125b (miRNA125b) function in astrogliosis and glial cell proliferation. Neurosci Lett 2010, 476:18-22.

58. Nikaki A, Piperi C, Papavassiliou AG: Role of microRNAs in gliomagenesis: targeting miRNAs in glioblastoma multiforme therapy. Expert Opin Investig Drugs 2012, 21:1475-1488.

59. Lukiw WJ: NF-kB-regulated micro RNAs (miRNAs) in primary human brain cells. Exp Neuro/ 2012, 235:484-490.

60. GeneCards: CDKN2A [http://www.genecards.org/cgi-bin/carddisp. pl?gene=CDKN2A]

61. Bykhovskaia M: Synapsin regulation of vesicle organization and functional pools. Semin Cell Dev Biol 2011, 22:387-392

62. Fassio A, Raimondi A, Lignani G, Benfenati F, Baldelli P: Synapsins: from synapse to network hyperexcitability and epilepsy. Semin Cell Dev Biol 2011 , 22:408-415.

63. Valtorta F, Pozzi D, Benfenati F, Fornasiero EF: The synapsins: multitask modulators of neuronal development. Semin Cell Dev Biol 2011, 22:378-386.

64. Yao PJ, Zhu M, Pyun El, Brooks Al, Therianos S, Meyers VE, Coleman PD: Defects in expression of genes related to synaptic vesicle trafficking in frontal cortex of Alzheimer's disease. Neurobiol Dis 2003, 12:97-109.

65. GeneCards: SYN2 [http://www.genecards.org/cgi-bin/carddisp. pl?gene=SYN2]

66. Lukiw WJ, Cui JG, Marcheselli VL, Bodker M, Botkjaer A, Gotlinger K, Serhan CN, Bazan NG: A role for docosahexaenoic acid-derived neuroprotectin D1 in neural cell survival and Alzheimer disease. J Clin Invest 2005, 115:2774-2783.

67. Lukiw WJ, Bazan NG: Docosahexaenoic acid and the aging brain. J Nutr 2008, 138:2510-2514

68. Zhao Y, Calon F, Julien C, Winkler JW, Petasis NA, Lukiw WJ, Bazan NG: Docosahexaenoic acid-derived neuroprotectin D1 induces neuronal survival via secretase- and PPARy-mediated mechanisms in Alzheimer's disease models. PLoS One 2011, 6:e15816

69. GeneCards: ALOX15 [http://www.genecards.org/cgi-bin/carddisp. pl?gene=ALOX15]

70. Taganov, KD, Boldin MP, Chang KJ, Baltimore D: NF-KB-dependent induction of miRNA miR-146, an inhibitor targeted to signaling proteins of innate immune responses. Proc Natl Acad Sci U S A 2006, 103:12481-12486.

71. Lee YJ, Han SB, Nam SY, Oh KW, Hong JT: Inflammation and Alzheimer's disease. Arch Pharm Res 2010, 33:1539-1556.

72. Li YY, Cui JG, Dua P, Pogue Al, Bhattacharjee S, Lukiw WJ:. Differential expression of miRNA-146a-regulated inflammatory genes in human primary neural, astroglial and microglial cells. Neurosci Lett 2011, 499:109-113.

73. Hill JM, Zhao Y, Clement C, Neumann DM, Lukiw WJ: HSV-1 infection of human brain cells induces miRNA-146a and Alzheimer-type inflammatory signaling. Neuroreport 2009, 20:1500-1505.

74. Lukiw WJ, Pogue Al: Induction of specific micro RNA (miRNA) species by ROS-generating metal sulfates in primary human brain cells. J Inorg Biochem 2007, 101:1265-1269.

75. GeneCards: CFH [http://www.genecards.org/cgi-bin/carddisp.pl?gene=CFH]

76. Flannery S, Bowie AG: The interleukin-1 receptor-associated kinases: critical regulators of innate immune signalling. Biochem Pharmacol 2010, 80:1981-1991.

77. Gan L, Li L: Regulations and roles of the interleukin-1 receptor associated kinases (IRAKs) in innate and adaptive immunity. Immunol Res 2006 35:295-302.

78. Sempere LF, Freemantle S, Pitha-Rowe I, Moss E, Dmitrovsky E, Ambros V: Expression profiling of mammalian miRNAs uncovers a subset of brainexpressed miRNAs with possible roles in murine and human neuronal differentiation. Genome Biol 2004, 5:R13.

79. GeneCards: IRAK1

[http://www.genecards.org/cgi-bin/carddisp.pl?gene=IRAK1]
80. Junge HJ, Yang S, Burton JB, Paes K, Shu X, French DM, Costa M, Rice DS, Ye W: TSPAN12 regulates retinal vascular development by promoting Norrinbut not Wnt-induced FZD4/beta-catenin signaling. Cell 2009, 139:299-311

81. Xu D, Sharma C, Hemler ME: Tetraspanin 12 regulates ADAM10-dependent cleavage of amyloid precursor protein. FASEB J 2009, 23:3674-3681.

82. GeneCards:TSPAN12 [http://www.genecards.org/cgi-bin/carddisp. pl?gene=TSPAN12]

83. Pogue Al, Percy ME, Cui JG, Li YY, Bhattacharjee S, Hill JM, Kruck TPA, Zhao Y, Lukiw WJ: Up-regulation of NF-kB-sensitive miRNA-125b and miRNA-146a in metal sulfate-stressed human astroglial (HAG) primary cell cultures. J Inorganic Biochem 2011, 105:1434-1437.

84. Li YY, Alexandrov PN, Pogue Al, Zhao Y, Bhattacharjee S, Lukiw WJ: miRNA-155 up-regulation and complement factor H (CFH) deficits in Down's syndrome. Neuroreport 2012, 23:168-173.

85. Poltronieri P, D'Urso PI, Mezzolla V, D'Urso OF: Potential of anti-cancer therapy based on anti-miR-155 oligonucleotides in glioma and brain tumours. Chem Biol Drug Des 2012. doi: 10.1111/cbdd.12002

86. Aronica E, Fluiter K, lyer A, Zurolo E, Vreijling J, van Vliet EA, Baayen JC, Gorte $J A$ : Expression pattern of miRNA-146a, an inflammation-associated microRNA, in experimental and human temporal lobe epilepsy. Eur $J$ Neurosci 2010, 31:1100-1107.

87. Sethi P, Lukiw WJ: Micro-RNA abundance and stability in human brain specific alterations in Alzheimer's disease temporal lobe neocortex. Neurosci Lett 2009, 459:100-104.

88. Lukiw WJ, Cui JG, Yuan LY, Bhattacharjee PS, Corkern M, Clement C, Kammerman EM, Ball MJ, Zhao Y, Sullivan PM, Hill JM: Acyclovir or A 342 peptides attenuate HSV-1-induced miRNA-146a levels in human primary brain cells. Neuroreport 2010, 21:922-927.

89. Hill JM, Ball MJ, Neumann DM, Azcuy AM, Bhattacharjee PS, Bouhanik S, Clement C, Lukiw WJ, Foster TP, Kumar M, Kaufman HE, Thompson HW: The high prevalence of herpes simplex virus type 1 DNA in human trigeminal ganglia is not a function of age or gender. J Virol 2008, 82:8230-8234.

90. Kammerman EM, Neumann DM, Ball MJ, Lukiw W, Hill JM: Senile plaques in Alzheimer's disease brains: possible association of beta-amyloid with herpes simplex virus type 1 (HSV-1) L-particles. Med Hypotheses 2006, 66:294-299.

91. Higaki S, Gebhardt B, Lukiw W, Thompson H, Hill J: Gene expression profiling in the HSV-1 latently infected mouse trigeminal ganglia following hyperthermic stress. Curr Eye Res 2003, 26:231-238.

92. Hill JM, Lukiw WJ, Gebhardt BM, Higaki S, Loutsch JM, Myles ME, Thompson HW, Kwon BS, Bazan NG, Kaufman HE: Gene expression analyzed by microarrays in HSV-1 latent mouse trigeminal ganglion following heat stress. Virus Genes 2001, 23:273-280.

93. Higaki S, Gebhardt BM, Lukiw WJ, Thompson HW, Hill JM: Effect of immunosuppression on gene expression in the HSV-1 latently infected mouse trigeminal ganglion. Invest Ophthalmol Vis Sci 2002, 43:1862-1869.

94. Wozniak MA, Frost AL, Preston CM, Itzhaki RF: Antivirals reduce the formation of key Alzheimer's disease molecules in cell cultures acutely infected with herpes simplex virus type 1. PLoS One 2011, 6:e25152.

95. Itzhaki RF, Wozniak MA: Could antivirals be used to treat Alzheimer's disease? Future Microbiol 2012, 7:307-309.

96. Ball MJ, Lukiw WJ, Kammerman E, Hill JM: Intracerebral propagation of Alzheimer's disease confirms its herpes virus etiology. Alzheimer's Dementia 2012. [Epub ahead of print]

97. Campbell A, Yang EY, Tsai-Turton M, Bondy SC: Pro-inflammatory effects of aluminum in human glioblastoma cells. Brain Res 2002, 933:60-65.

98. Exley C: Aluminium, tau and Alzheimer's disease. J Alzheimers Dis 2007 12:313-315.

99. Walton JR: Aluminum disruption of calcium homeostasis and signal transduction resembles change that occurs in aging and Alzheimer's disease. J Alzheimers Dis 2012, 29:255-273.

100. Percy ME, Kruck TP, Pogue Al, Lukiw WJ: Towards the prevention of potential aluminum toxic effects and an effective treatment for Alzheimer's disease. J Inorg Biochem 2011, 105:1505-1512.

101. Kawahara M, Kato-Negishi M: Link between aluminum and the pathogenesis of Alzheimer's disease: the integration of the aluminum and amyloid cascade hypotheses. Int J Alzheimers Dis 2011, 2011:276393.

102. Pogue Al, Li YY, Cui JG, Zhao Y, Kruck TP, Percy ME, Tarr MA, Lukiw WJ: Characterization of an NF-KB-regulated, miRNA-146a-mediated downregulation of complement factor $\mathrm{H}(\mathrm{CFH})$ in metal-sulfate-stressed human brain cells. J Inorg Biochem 2009, 103:1591-1595. 
103. Zhang QL, Jia L, Jiao X, Guo WL, Ji JW, Yang HL, Niu Q: APP/PS1 transgenic mice treated with aluminum: an update of Alzheimer's disease model. Int $J$ Immunopathol Pharmacol 2012, 25:49-58.

104. Lukiw WJ: Evidence supporting a biological role for aluminum in brain chromatin compaction and epigenetics. J Inorg Biochem 2010, 104:1010-1012.

105. Percy ME, KruckTP, Pogue Al, Lukiw WJ: Towards the prevention of potential aluminum toxic effects and an effective treatment for Alzheimer's disease. J Inorg Biochem 2011, 105:1505-1512.

106. Alexandrov PN, Zhao Y, Pogue Al, Tarr MA, Kruck TP, Percy ME, Cui JG, Lukiw WJ: Synergistic effects of iron and aluminum on stress-related gene expression in primary human neural cells. J Alzheimers Dis 2005, 8:117-127.

107. Lukiw WJ, Percy ME, Kruck TP: Nanomolar aluminum induces proinflammatory and pro-apoptotic gene expression in human brain cells in primary culture. J Inorg Biochem 2005, 99:1895-1898.

108. Pogue Al, Jones BM, Bhattacharjee S, Percy ME, Zhao Y, Lukiw WJ: Metalsulfate induced generation of ROS in human brain cells: detection using an isomeric mixture of 5- and 6-carboxy-2,7'-dichlorofluorescein diacetate (carboxy-DCFDA) as a cell permeant tracer. Int J Mol Sci 2012, 13:9615-9626.

109. Kruck TP, Cui JG, Percy ME, Lukiw WJ: Molecular shuttle chelation: the use of ascorbate, desferrioxamine and Feralex-G in combination to remove nuclear bound aluminum. Cell Mol Neurobiol 2004, 24:443-459.

110. Alexandrov PN, Zhao Y, Pogue Al, Tarr MA, Kruck TP, Percy ME, Cui JG, Lukiw
WJ: Synergistic effects of iron and aluminum on stress-related gene expression in primary human neural cells. J Alzheimers Dis 2005, 8:117-127.

111. Lane RF, Shineman DW, Steele JW, Lee LB, Fillit HM: Beyond amyloid: the future of therapeutics for Alzheimer's disease. Adv Pharmaco/ 2012, 64:213-271.

112. Ansari N, Khodagholi F: Molecular mechanism aspect of ER stress in Alzheimer's disease: current approaches and future strategies. Curr Drug Targets 2012. [Epub ahead of print]

113. Schenk D, Basi GS, Pangalos MN: Treatment strategies targeting amyloid ß-protein. Cold Spring Harb Perspect Med 2012, 2:a006387.

114. Sharma HS, Castellani RJ, Smith MA, Sharma A: The blood-brain barrier in Alzheimer's disease: novel therapeutic targets and nanodrug delivery. Int Rev Neurobiol 2012, 102:47-90.

115. Rüegger S, Großhans H: MicroRNA turnover: when, how, and why. Trends Biochem Sci 2012, 37:436-446.

116. Zhang Z, Qin YW, Brewer G, Jing Q: MicroRNA degradation and turnover: regulating the regulators. Wiley Interdiscip Rev RNA 2012, 3:593-600.

doi:10.1186/alzrt150

Cite this article as: Lukiw WJ: NF-kB-regulated, proinflammatory miRNAs in

Alzheimer's disease. Alzheimer's Research \& Therapy 2012, 4:47. 